\title{
The effect of paternal age on pregnancy outcomes in ovum donation cycles
}

\author{
Lena Sagi-Dain ${ }^{1,2 *}$, Eran Segev ${ }^{1}$, Kamal Ojha ${ }^{3,4}$, David Bider ${ }^{5}$, Jacob Levron ${ }^{5}$, Viktor Zinchenko ${ }^{6}$, Sharon Walster and Martha Dirnfeld ${ }^{1,2}$ \\ ${ }^{1}$ Division of Fertility-In Vitro Fertilization, Department of Obstetrics and Gynecology, Carmel Medical Center, Haifa, Israel \\ ${ }^{2}$ Faculty of Medicine, Technion, Haifa, Israel \\ ${ }^{3}$ St Georges Hospital, London, UK \\ ${ }^{4}$ The London Bridge Gynecology Fertility and Genetic Centre, London, UK \\ ${ }^{5}$ In Vitro Fertilization Centre, Isida, Kiev, Ukraine \\ ${ }^{6}$ Division of Fertility-In Vitro Fertilization, Sheba Medical Centre, Faculty of Medicine, Tel Aviv, Israel
}

\begin{abstract}
Objective: To evaluate the effect of paternal age on clinical outcomes in ovum donation recipients.

Methods: Retrospective cohort analysis of 746 ovum donation cycles was conducted in two private in vitro fertilization centers between 2005 and 2012.

Results: When comparing between $\geq 50$ years and $<40$ years paternal age groups, a significant decline in clinical pregnancy rates $(27.3 \%$ vs. $37.8 \%$, OR $0.62(95 \% \mathrm{CI}$ $0.39-0.95)$ ), live birth rates (56.1\% vs. $67.4 \%$, respectively, OR 0.59 (95\% CI $0.37-0.96))$ and in multiple gestation rates (22.5\% vs. $38.8 \%$, respectively, OR 0.39 (95\% CI 0.16-0.98)) was noted. The groups did not differ in other pregnancy outcomes.

Conclusion: In light of these results, together with previous investigations, it is desirable to set up a consortium to study how to establish counseling for older fathers as well as older couples undergoing in vitro fertilization.
\end{abstract}

\begin{abstract}
Abbreviations: ART: Assisted reproductive techniques; APA: Advanced paternal age; ICSI: Intracytoplasmic sperm injection; HFEA: Human Fertilization and Embryology Authority; IVF: In vitro fertilization; EV: Estradiol valerate; SD: Standard Deviations; IMSI: Intracytoplasmic injection of morphologically selected spermatozoa; MSOME: Motile Sperm Organelle Morphology Examination
\end{abstract}

\section{Introduction}

Nowadays, couples tend to conceive at an older age. In the USA birth rates to fathers aged 35-54 years increased by nearly $30 \%$ between the years 1980 and 2000 [1]. A similar trend was shown in England and Wales [2]. Factors that may influence the age at which the parents have their first baby include educational, social and economic status. In addition, assisted reproductive techniques (ART) enable older couples to realize their aspirations for a healthy offspring later in life. However, this delay is not without complications. The negative impact of advanced maternal age on fertility, including increased rates of miscarriage, chromosomal aberrations, congenital anomalies, obstetrical complications and adverse perinatal and post-natal outcomes of offspring, has been extensively studied and well established [3-6]. Moreover, increasing age of the mother has been shown to adversely affect ART outcomes $[7,8]$.

In contrast to the extensive data on the relationship between maternal age and reproductive outcomes, relatively few studies have addressed the influence of advanced paternal age (APA) on reproductive outcome. Moreover, the available data are conflicting. A review of 10 leading studies addressing the effect of paternal age on reproductive outcomes has demonstrated an age-related decrease in semen parameters, mainly semen volume [9]. However, most of the studies failed to demonstrate a clear and significant correlation between APA and adverse reproductive outcomes. Nevertheless, APA has been reported to be associated with an increased risk of miscarriage and obstetrical complications, such as preeclampsia and low birth weight [10-12].

Analysis of cycles using ovum donation by young healthy fertile women enables a useful model to study the effect of paternal age on fertility, as it rules out maternal age, major confounding factor that negatively impacts fertility outcome. The intracytoplasmic sperm injection (ICSI) technique may help to overcome sperm defects and age-related decline in testicular function [13]. However, only few studies with relatively small numbers have used this model, and the reported results are contradictory [9].

The purpose of the present study was to investigate associations between advancing paternal age and pregnancy outcomes in couples undergoing ovum donation.

\section{Materials and methods}

The study data were collected retrospectively from a computerized database. All oocyte donation cycles performed between June 2005 and October 2012 at two private in vitro fertilization centers were reviewed.

*Correspondence to: Lena Sagi-Dain, M.D., Department of Obstetrics and Gynecology, Carmel Medical Center, 7 Michal St., Haifa, Israel, Tel: +972506265842; Fax: +972-48258075; E-mail: lena2303@gmail.com

Key words: paternal age, ovum donation, clinical pregnancy, live birth

Received: June 13, 2021; Accepted: June 28, 2021; Published: June 30, 2021 
Ovum donations were received from healthy and fertile young donors aged 30 years or less. Donors underwent screening tests according to institute protocols and based on Human Fertilization and Embryology Authority (HFEA) guidelines, including tests for infectious diseases and genetic tests for cystic fibrosis and Fragile X, and signed an informed consent form before starting a treatment cycle.

The protocol for ovarian stimulation, ovum retrieval, in vitro fertilization (IVF)-ICSI and embryo handling in the laboratory was performed as previously described [14]. All mature MII oocytes were inseminated by ICSI. Fresh or frozen thawed semen samples of the recipient partner were used. Embryos were classified according to the number of blastomers and their appearance and by the percentage of fragmentation. The best-graded fresh embryos were selected for embryo transfer, and the rest were frozen. Embryos were transferred on day 2 or 3 , and in a few cycles with repeated implantation failure blastocyst transfer was performed.

All recipients underwent genetic counseling and general health assessments. Welfare of the child forms from their general practitioners was mandatory as per the HFEA code of practice. The protocol for hormonal treatment for recipients was maintained as previously described [15]. Briefly, recipients received a starting dose of $6 \mathrm{mg}$ estradiol valerate (EV) daily. For recipients with a menstrual cycle, oral contraceptive pill or GnRH agonist (IM decapeptyl, $3.75 \mathrm{mg}$ ) were used for synchronization. Vaginal progesterone (Utrogestan 800 $\mathrm{mg} / \mathrm{d}$ [micronized progesterone]; Besin International Laboratories) was started on the day of donor oocyte retrieval. All embryo transfers were performed under ultrasound guidance. Following a positive $\beta$ hCG test result, recipients were scheduled an ultrasound examination at 6-7 weeks of pregnancy. A confirmation of clinical pregnancy was made by visualization of a gestational sac and the presence of a fetal heartbeat. A miscarriage was defined as a clinical pregnancy loss before gestational week 12. Biochemical pregnancy was determined by an initial rise, followed by a decrease in serum $\beta$ hCG levels, without any sonographic findings.

Paternal age ranges were divided into 3 groups: $<40$ years, between 40 and 49 years, and $\geq 50$ years of age. Parameters analyzed in each group included: recipient endometrial thickness, mean number of embryos transferred, fertilization rates, cleavage rates, number of embryos with 7 or more cells on day 3 , pregnancy rate, pregnancy loss in terms of chemical and missed abortion, and live birth and multiple pregnancy rates.

No more than 2 embryos were transferred on the first ovum donation cycle. In certain circumstances, such as history of repeated implantation failure with previous attempts, 3 embryos were transferred.

Statistical analysis was performed by using PASW 18 software. The continuous variables were presented by mean, median \& Standard Deviations (SD). The categorical variables were presented in percentages. Chi square test was used to compare between the categorical variables. The continuous variables were analyzed using One Way ANOVA or Kruskal-Wallis (as appropriate), followed by Mann-Whitney with Bonferroni correction. $\mathrm{P}<0.05$ was considered statistically significant.

\section{Results}

A total of 746 ovum recipient cycles were included in the study. The cycles were performed for the following indications: advanced maternal age ( $>44$ years) ( 369 cycles, $49.5 \%$ ), failure to conceive after more than four IVF cycles (228 cycles, $30.5 \%)$, premature ovarian failure (48 cycles, $6.5 \%$ ) or menopause (64 cycles, $8.6 \%$ ), and repeated miscarriage
(37 cycles, $5 \%$ ). Recipient age averaged $43.9 \pm 4.6$ years (ranging from 25 to 56 years), and mean male age $-43.84 \pm 7.8$ years. Diagnostic procedures exhibited normal uterine anatomy in 435 cycles $(58.5 \%)$, while fibroid uterus was diagnosed in 264 cycles (35.5\%), endometrial polyps in 29 cycles $(3.9 \%)$, and intrauterine adhesions in 16 cycles $(2.2 \%)$. Out of 239 recipients, $148(62 \%)$ were previously treated in other centers. In our center, 201 recipients $(68 \%)$ had more than one embryo transfer, and 106 had more than 2 embryo transfers. Of 676 cycles in which endometrial grade was noted, 170 had grade A scores (25.1\% of the assessments), 458 (67.8\%) grade B, and 48 (7.1\%) grade $\mathrm{C}$ scores. Endometrial thickness was noted in 735 cycles and averaged $8.59 \pm 2.0 \mathrm{~cm}$. In recipients with repeated implantation failures, local endometrial injury by Pipelle catheter was performed in $133(17.8 \%)$ of ovum donation cycles, and hysteroscopy - in 315 (42.2) of the cases.

The mean day of embryo transfer $(\mathrm{ET})$ was $2.67 \pm 0.58$ days, and the mean number of transferred embryos per cycle was $2.55 \pm 0.65$. The number of fresh ET cycles was 636 (85.5\% of the procedures), while the remaining involved frozen embryo transfer (FET) (45 cycles, $6 \%$ ) or combined fresh and FET (63 cycles, 8.5\%).

The 746 oocyte retrieval-embryo transfer cycles resulted in 287 pregnancies $(38.5 \%)$. Of them, 46 ended in biochemical pregnancies (16.0\% of pregnancies), two were ectopic $(0.7 \%), 53$ resulted in spontaneous miscarriages (18.5\%), three (1.1\%) terminated in stillbirth, and 183 resulted in live births (63.8\%), 61 (33\%) of which were multiple order gestations. Fresh embryo transfers achieved significantly more pregnancies than did frozen embryo transfers (32.4\% vs. $10.6 \%$ ), while combined embryo transfers resulted in clinical pregnancy in $21.2 \%$ of the cycles.

Table 1 presents the characteristics of the cycles according to paternal age as follows: 222 men $<40$ years, 359 men $40-49$ years and 165 men $\geq 50$ years. Not surprisingly, a significant increase was noted

Table 1. Characteristics of the cycles according to paternal age Values are presented as means \pm standard deviations unless noted otherwise.

\begin{tabular}{|c|c|c|c|c|}
\hline Parameter & $\begin{array}{c}<40 \\
\mathrm{~N}=\mathbf{2 2 2}\end{array}$ & $\begin{array}{c}40-49 \\
N=359\end{array}$ & $\begin{array}{l}\geq 50 \\
\mathrm{~N}=165\end{array}$ & $\mathbf{p}$ \\
\hline Female age (years) & $41.6 \pm 5.3$ & $43.75 \pm 3.4$ & $47.65 \pm 3.49$ & $<0.0001^{\mathrm{a}}$ \\
\hline Male age (years) & $35.4 \pm 3.1$ & $43.79 \pm 2.6$ & $55.3 \pm 4.6$ & \\
\hline Pipelle - n (\%) & $39(17.6)$ & $68(18.9)$ & $26(15.8)$ & 0.671 \\
\hline Hysteroscopy $-\mathrm{n}(\%)$ & $89(40.1)$ & $142(39.6)$ & $84(50.9)$ & $0.038^{b}$ \\
\hline Endometrial thickness (mm) & $\begin{array}{c}\mathrm{N}=218 \\
8.49 \pm 1.7\end{array}$ & $\begin{array}{c}\mathrm{N}=354 \\
8.63 \pm 2.2\end{array}$ & $\begin{array}{c}\mathrm{N}=163 \\
8.62 \pm 1.75\end{array}$ & 0.689 \\
\hline $\begin{array}{c}\text { No. of embryos transferred } \\
\text { Median (range) }\end{array}$ & $\begin{array}{l}\mathrm{N}=221 \\
2(1-8)\end{array}$ & $\begin{array}{l}\mathrm{N}=359 \\
3(1-6)\end{array}$ & $\begin{array}{l}\mathrm{N}=164 \\
3(1-5)\end{array}$ & $0.015^{\mathrm{c}}$ \\
\hline Type of embryo transfer & 221 & 359 & 164 & \\
\hline Fresh $-\mathrm{n}(\%)$ & $188(85.1)$ & $310(86.4)$ & $138(84.1)$ & \\
\hline Frozen $-\mathrm{n}(\%)$ & $14(6.3)$ & $16(4.5)$ & $15(9.1)$ & 0.284 \\
\hline Combined $-\mathrm{n}(\%)$ & $19(8.6)$ & $33(9.2)$ & $11(6.7)$ & \\
\hline Uterine factor & $\mathrm{N}=222$ & $\mathrm{~N}=357$ & $\mathrm{~N}=165$ & \\
\hline None $-\mathrm{n}(\%)$ & $150(67.6)$ & $201(56.3)$ & $84(50.9)$ & \\
\hline Fibroid - n (\%) & $65(29.3)$ & $126(35.3)$ & $73(44.2)$ & $0.002^{\mathrm{d}}$ \\
\hline Polyp -n (\%) & $7(3.2)$ & $15(4.2)$ & $7(4.2)$ & \\
\hline Adhesions $-\mathrm{n}(\%)$ & 0 & $15(4.2)$ & $1(0.6)$ & \\
\hline $\begin{array}{c}\text { Endometrial grade } \\
\text { A n }(\%) \\
\text { B n (\%) } \\
\text { C n }(\%)\end{array}$ & $\begin{array}{c}\mathrm{N}=202 \\
53(26.2) \\
136(67.3) \\
13(6.4)\end{array}$ & $\begin{array}{c}\mathrm{N}=328 \\
83(25.3) \\
224(68.3) \\
21(6.4)\end{array}$ & $\begin{array}{c}\mathrm{N}=146 \\
34(23.3) \\
98(67.1) \\
14(9.6)\end{array}$ & 0.745 \\
\hline
\end{tabular}

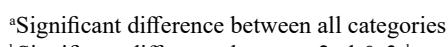



'Significant difference between the $1^{\text {st }} \& 2^{\text {nd }}$ categories ( $<40$ vs. $\left.40-49\right)$

${ }^{\mathrm{d}}$ The p-value relates to difference between none vs. all other uterine factor 
Table 2. Pregnancy outcomes according to paternal age groups

\begin{tabular}{|c|c|c|c|c|c|c|}
\hline Parameter & $\begin{array}{c}<40 \text { years } \\
\mathrm{N}=222\end{array}$ & $\begin{array}{c}\text { 40-49 years } \\
N=359\end{array}$ & $\begin{array}{c}\geq 50 \text { years } \\
N=165\end{array}$ & $\mathbf{p}^{\mathrm{a}}$ & OR $(95 \% \mathrm{CI})^{\mathrm{b}}$ & $\mathbf{p}^{\mathrm{b}}$ \\
\hline Pregnancy & $95(42.8 \%)$ & $135(37.6 \%)$ & $57(34.5 \%)$ & 0.230 & $0.71(0.47-1.07)$ & 0.115 \\
\hline Clinical pregnancy & $84(37.8 \%)$ & $112(31.2 \%)$ & $45(27.3 \%)$ & 0.073 & $0.62(0.39-0.95)$ & 0.029 \\
\hline \multicolumn{7}{|l|}{ Pregnancy outcomes } \\
\hline Live birth & $64(67.4 \%)$ & $87(64.4 \%)$ & $32(56.1 \%)$ & 0.101 & $0.59(0.37-0.96)$ & 0.043 \\
\hline Multiple gestation & $25(38.8 \%)$ & $29(33.7 \%)$ & $7(22.5 \%)$ & 0.206 & $0.39(0.16-0.98)$ & 0.015 \\
\hline Biochemical pregnancy & $11(11.6 \%)$ & $23(17.0 \%)$ & $12(21.1 \%)$ & 0.277 & $1.8(0.75-4.39)$ & 0.388 \\
\hline Early miscarriage & $18(18.9 \%)$ & $22(16.3 \%)$ & $13(22.8 \%)$ & 0.563 & $1.1(0.52-2.4)$ & 1.00 \\
\hline Ectopic pregnancy & 0 & $2(1.5 \%)$ & 0 & N/A & $\mathrm{N} / \mathrm{A}$ & $\mathrm{N} / \mathrm{A}$ \\
\hline Stillborn & $2(2.1 \%)$ & $1(0.7 \%)$ & 0 & N/A & N/A & $\mathrm{N} / \mathrm{A}$ \\
\hline
\end{tabular}

OR - Odds Ratio, CI - Confidence Interval, N/A - Not amenable to calculation due to small numbers

a - chi squared test

$\mathrm{b}$ - for comparison between males $\geq 50$ years and $<40$ years

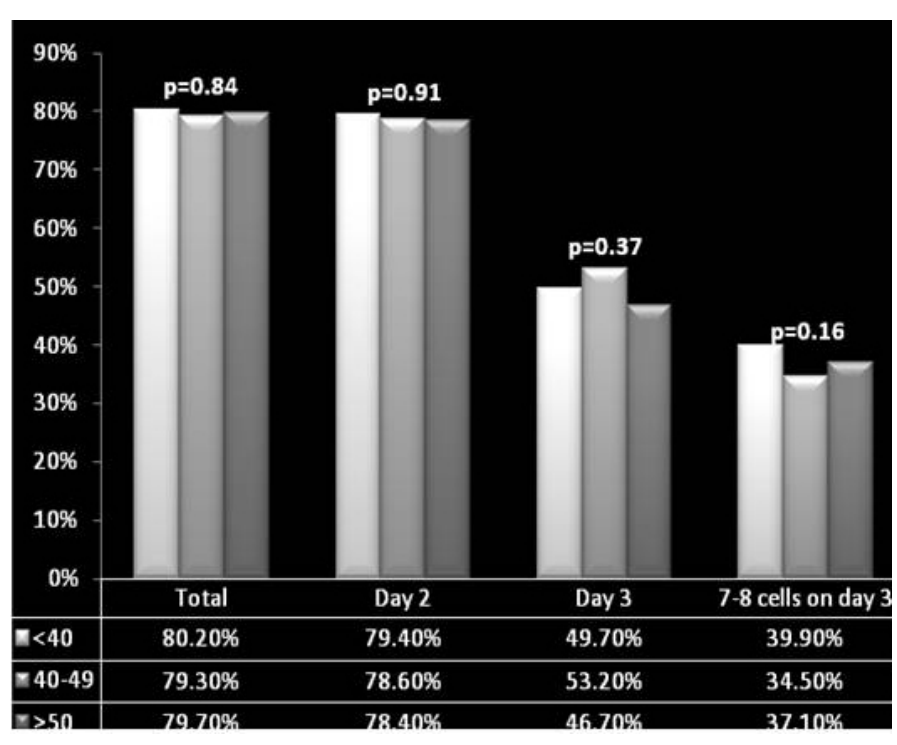

Figure 1. Graphical Representation

in average recipients' age with rising male age. Female partners of older males exhibited significantly higher rates of intra-uterine pathology and underwent more hysteroscopic procedures compared to younger couples. In addition, higher number of embryos was transferred in older couples. The three groups did not differ in terms of endometrial thickness or grades, numbers of Pipelle procedures, or the type of embryo transfer.

Fertilization rates did not differ significantly between the three groups, regardless of whether fresh or thawed semen was used for ICSI. Similarly, cleavage rate on day 2 and day 3 and number of embryos with 7-8 cells on day 3 did not differ among the groups.

Table 2 compares pregnancy outcomes in the three paternal age groups. Although a decline in pregnancy rates was noted with advancing male age $(42.8 \%$ in males under 40 years of age, $37.6 \%$ at 40-49 years, and $34.5 \%$ above 49 years), this difference exhibited no statistical significance $(\mathrm{p}=0.23)$. Similarly, a non-significant decline in clinical pregnancy rates was found with increasing paternal age $37.8 \%$, $31.2 \%$ and $27.3 \%$, respectively, $\mathrm{p}=0.073$ ). However, when comparing between the $\geq 50$ years and $<40$ years groups, a significant decline in clinical pregnancy rates (OR 0.62 (95\% CI 0.39-0.95)), live birth rates (56.1\% vs. $67.4 \%$, respectively, OR 0.59 (95\% CI $0.37-0.96)$ ) and in multiple gestation rates $(22.5 \%$ vs. $38.8 \%$, respectively, OR $0.39(95 \%$ CI 0.16-0.98)) was noted. The groups did not differ in other pregnancy outcomes (Figure 1).

\section{Discussion}

The results of our study demonstrated significantly lower rates of clinical pregnancy and live birth with paternal age $\geq 50$ years, compared to $<40$ years group, despite the seemingly similar success of fertilization and embryo cleavage. These observations are supported by several other studies. For instance, Frattarelli JL, et al. examined the largest cohort of 1,023 anonymous oocyte donation cycles and demonstrated a significant decrease in live birth rate in men $>50$ years of age accompanied by an increase in pregnancy loss, yet with no statistically significant difference in fertilization rates [16]. In addition, the authors reported decreased blastocyst formation rates, despite the unaffected initial embryo morphology through the cleavage stage. Similarly, Luna $\mathrm{M}$, et al. demonstrated in 672 cycles that blastocyst formation rate significantly decreased as partner's age progressed [17]. These investigators also noted a significant decline in implantation rates and a trend toward a lower clinical pregnancy rates and a higher miscarriage rates for men $>60$ years. Recently, Robertshaw I, et al. demonstrated a significant decline in live birth rate with increasing paternal age in a total of 237 ovum donor cycles [18]. Of note, two earlier studies found no association between male age and fertilization rate, embryo quality, implantation, pregnancy, or live birth rate $[19,20]$.

The shared observation of the lack of the effect of paternal age on embryo cleavage is not surprising, since early embryo development through the cleavage stage is influenced mainly by the maternal genome [21]. However, studies that assessed embryo development beyond the cleavage stage, i.e. during time of male genome activation, reported a significant decrease in blastocyst formation rate with advancing paternal age. This adverse influence could be related to higher risk of numerical and structural aberrations in sperm from older men, partially explained by increased chromosomal nondisjunction $[22,23]$. In addition, numerous autosomal dominant disorders have been linked to APA, such as achondroplasia, craniosynostosis syndromes, and Marfan syndrome [24,25]. Children of older couples have been reported to have an increased risk of dying from congenital malformations and malignancies [26], as well as higher risks of autism, schizophrenia, epilepsy, and neurodevelopmental disorders [27-32]. Possible underlying mechanisms for such associations may include accumulation of environmental damage, epigenetic changes in the germ cells of older fathers, reduced efficiency of DNA repair and increased genomic instability, hormonal influences, suppressed apoptosis, or decreased effectiveness of antioxidants and micronutrients $[23,33]$. In addition, Tiemann-Boege, et al. hypothesized that "Selfish Spermatogonial Selection" may positively select rare spermatogonial cells bearing mutations, and lead to their progressive clonal expansion [34]. 
The emergence of ART combined with the growing tendency of older men to have children leaves unsolved questions and raises medical as well as ethical dilemmas. ICSI has evolved as a powerful technique to overcome male infertility, including problems related to advanced paternal age. This method is able to overcome the most dramatic decreases in semen parameters, which could be a possible expression of natural selection process. In the absence of advanced techniques to analyze single spermatozoa prior to ICSI, sperm selection is based mainly on gross morphology. This method is suboptimal for detection of epigenetic changes, chromosomal aberrations and single gene mutations found in higher rates in the sperm from older males [35]; and can lead to problems in offspring of the first and even second generation. If true, the burden on the society and healthcare services may grow exponentially.

It has been demonstrated that intracytoplasmic injection of morphologically selected spermatozoa (IMSI( by means of a high magnification sperm selection method (Motile Sperm Organelle Morphology Examination - MSOME, using 1000-6000× magnification) can reduce the risk of major malformations [36,37]. However, a recent Cochrane review showed no benefit from the use of IMSI [38]. Moreover, IMSI has not been tested specifically in sperm from older men. More studies are needed to identify complementary and reliable techniques for sperm selection prior to ICSI.

The value of our study is the contribution of large cohort based information to the limited pool of evidence regarding the effects of paternal age on ART results, after controlling for female age with use of the donor oocyte model. As older women tend to reproduce with older partners, using the ovum donation-IVF-ICSI model isolates the effect of advancing paternal age gametes on fertilization and pregnancy outcome. Our cohort is one of the largest that have used the oocyte donation model, and includes the largest number of males $\geq 50$ years of age.

The relatively low clinical pregnancy rates are due to the population of this program which included a majority of recipients $(>65 \%)$ with repeated implantation failures.

An important limitation of all the existing reports examining the effects of paternal age in oocyte donation model, including our trial, is the retrospective design of data collection. Another limitation of our investigation is lack of embryo quality evaluation at blastocyst stage. During the study period, embryo transfer was performed mainly during cleavage stage. The main reason for that was the nature of the program (a cross border reproductive care), which limited the duration of recipients' stay at the IVF center, while, at that time, the technique of blastocyst vitrification was not routinely available. Additional finding worth mentioning is the significant, though expected, higher maternal age with rising male age. Although oocyte donation is supposed to eliminate this crucial confounder, and despite the same endometrial sonographic appearance between the varying paternal age groups, higher recipients' age could still influence the endometrial environment in terms of other non-measured parameters, such as cytokine and growth factor levels. Finally, follow-up of offspring according to paternal age is an important area of research that was not within the scope of the current study.

\section{Conclusions}

Advanced paternal age might have an adverse effect on pregnancy outcomes in ovum donation cycles. While advanced maternal age is an indication for genetic and pre-gestational counseling, no clear definitions or guidelines on such evaluation have been established for advanced paternal age. In light of our results, together with previous analyses, it is recommended to set up a consortium that will recommend counseling of older fathers, let alone, aged couples, and set up a standard of care and routine screening tests. Research should be focused to identify the optimal outcome-based counseling for older couples undergoing IVF.

\section{Declarations}

\section{Acknowledgements}

None.

\section{Ethics approval and consent to participate}

The study was approved by Local Ethics Committee of Isida Hospital (date of approval July 15, 2015, No. 437).

\section{Consent for publication}

Not applicable.

\section{Availability of data and materials}

The data that support the findings of this study are available on request from the corresponding author [MD]. The data are not publicly available due to privacy restrictions.

\section{Competing interests}

The authors declare that they have no competing interests.

\section{Funding}

No funding was used for the research.

\section{Authors' contributions}

Lena Sagi-Dain, Eran Segev and Martha Dirnfeld contributed to conception and design, analysis and interpretation of data and drafting the article.

Kamal Ojha, David Bider, Jacob Levron, Viktor Zinchenko, and Sharon Walster contributed to data collection, revising the article, providing intellectual content of critical importance to the work described and final approval of the version to be published.

\section{References}

1. Ventura SJ, Hamilton BE, Sutton PD (2003) Revised birth and fertility rates for the United States, 2000 and 2001. Natl Vital Stat Rep 51: 1-18. [Crossref]

2. Statistics (2002) Birth statistics: review of the registrar general on births and family building patterns in England and Wales. Stationery Office, London.

3. Munne S, Alikani M, Tomkin G, Grifo J, Cohen J (1995) Embryo morphology, developmental rates, and maternal age are correlated with chromosome abnormalities. Fertil Steril 64: 382-391. [Crossref]

4. Cnattingius S, Forman MR, Berendes HW, Isotalo L (1992) Delayed childbearing and risk of adverse perinatal outcome. A population-based study. JAMA 268: 886-890. [Crossref]

5. Nybo AA, Wohlfahrt J, Christens P, Olsen J, Melbye M (2000) Is maternal age an independent risk factor for fetal loss? West J Med 173: 331. [Crossref]

6. Jacobsson B, Ladfors L, Milsom I (2004) Advanced maternal age and adverse perinatal outcome. Obstet Gynecol 104: 727-733. [Crossref]

7. Dew JE, Don RA, Hughes GJ, Johnson TC, Steigrad SJ (1998) The influence of advanced age on the outcome of assisted reproduction. J Assist Reprod Genet 15: 210214. [Crossref]

8. Pantos K, Athanasiou V, Stefanidis K, Stavrou D, Vaxevanoglou T, et al. (1999) Influence of advanced age on the blastocyst development rate and pregnancy rate in assisted reproductive technology. Fertil Steril 71: 1144-1146. [Crossref] 
9. Dain L, Auslander R, Dirnfeld M (2011) The effect of paternal age on assisted reproduction outcome. Fertil Steril 95: 1-8. [Crossref]

10. Kleinhaus K, Perrin M, Friedlander Y, Paltiel O, Malaspina D, et al. (2006) Paternal age and spontaneous abortion. Obstet Gynecol 108: 369-377. [Crossref]

11. Harlap S, Paltiel O, Deutsch L, Knaanie A, Masalha S, et al. (2002) Paternal age and preeclampsia. Epidemiology 13: 660-667. [Crossref]

12. Reichman NE, Teitler JO (2006) Paternal age as a risk factor for low birthweight. Am J Public Health 96: 862-866. [Crossref]

13. Nagy ZP, Liu J, Joris H, Verheyen G, Tournaye H, et al. (1995) The result of intracytoplasmic sperm injection is not related to any of the three basic sperm parameters. Hum Reprod 10: 1123-1129. [Crossref]

14. Pellicer A, Simon C, Miro F, Castellvi RM, Ruiz A, et al. (1989) Ovarian response and outcome of in-vitro fertilization in patients treated with gonadotrophin-releasing hormone analogues in different phases of the menstrual cycle. Hum Reprod 4: 285-289. [Crossref]

15. Remohi J, Gutierrez A, Cano F, Ruiz A, Simon C, et al. (1995) Long oestradiol replacement in an oocyte donation programme. Hum Reprod 10: 1387-1391. [Crossref]

16. Frattarelli JL, Miller KA, Miller BT, Elkind-Hirsch K, Scott RT, Jr (2008) Male age negatively impacts embryo development and reproductive outcome in donor oocyte assisted reproductive technology cycles. Fertil Steril 90: 97-103. [Crossref]

17. Luna M, Finkler E, Barritt J, Bar-Chama N, Sandler B, et al. (2009) Paternal age and assisted reproductive technology outcome in ovum recipients. Fertil Steril 92: 17721775. [Crossref]

18. Robertshaw I, Khoury J, Abdallah ME, Warikoo P, Hofmann GE (2014) The effect of paternal age on outcome in assisted reproductive technology using the ovum donation model. Reprod Sci 21: 590-593. [Crossref]

19. Gallardo E, Simon C, Levy M, Guanes PP, Remohi J, et al. (1996) Effect of age on sperm fertility potential: oocyte donation as a model. Fertil Steril 66: 260-264. [Crossref]

20. Paulson RJ, Milligan RC, Sokol RZ (2001) The lack of influence of age on male fertility. Am J Obstet Gynecol 184: 818-822.

21. Agostoni E (1993) Preimplantation development of the mammalian embryo. Ann Ist Super Sanita 29: 15-25. [Crossref]

22. Sartorelli EM, Mazzucatto LF, de Pina-Neto JM (2001) Effect of paternal age on human sperm chromosomes. Fertil Steril 76: 1119-1123. [Crossref]

23. Sloter E, Nath J, Eskenazi B, Wyrobek AJ (2004) Effects of male age on the frequencies of germinal and heritable chromosomal abnormalities in humans and rodents. Fertil Steril 81: 925-943. [Crossref]
24. Penrose LS (1955) Parental age and mutation. Lancet 269: 312-313. [Crossref]

25. Jones KL, Smith DW, Harvey MA, Hall BD, Quan L (1975) Older paternal age and fresh gene mutation: data on additional disorders. J Pediatr 86: 84-88. [Crossref]

26. Urhoj SK, Jespersen LN, Nissen M, Mortensen LH, Nybo Andersen AM (2014) Advanced paternal age and mortality of offspring under 5 years of age: a register-based cohort study. Hum Reprod 29: 343-350. [Crossref]

27. Reichenberg A, Gross R, Weiser M, Bresnahan M, Silverman J, et al. (2006) Advancing paternal age and autism. Arch Gen Psychiatry 63: 1026-1032. [Crossref]

28. Buizer-Voskamp JE, Laan W, Staal WG, Hennekam EA, Aukes MF, et al. (2011) Paternal age and psychiatric disorders: findings from a Dutch population registry. Schizophr Res 129: 128-32. [Crossref]

29. Miller B, Messias E, Miettunen J, Alaraisanen A, Jarvelin MR, et al. (2011) Metaanalysis of paternal age and schizophrenia risk in male versus female offspring. Schizophr Bull 37: 1039-1047. [Crossref]

30. Vestergaard M, Mork A, Madsen KM, Olsen J (2005) Paternal age and epilepsy in the offspring. Eur J Epidemiol 20: 1003-1005. [Crossref]

31. Saha S, Barnett AG, Foldi C, Burne TH, Eyles DW, et al. (2009) Advanced paternal age is associated with impaired neurocognitive outcomes during infancy and childhood. PLoS Med 6: e40. [Crossref]

32. Malaspina D, Reichenberg A, Weiser M, Fennig S, Davidson M, et al. (2005) Paternal age and intelligence: implications for age-related genomic changes in male germ cells. Psychiatr Genet 15: 117-125. [Crossref]

33. Adkins RM, Thomas F, Tylavsky FA, Krushkal J (2011) Parental ages and levels of DNA methylation in the newborn are correlated. BMC Med Genet 12: 47. [Crossref]

34. Tiemann-Boege I, Navidi W, Grewal R, Cohn D, Eskenazi B, Wyrobek AJ, et al. The observed human sperm mutation frequency cannot explain the achondroplasia paternal age effect. Proc Natl Acad Sci U S A 99: 14952-14957. [Crossref]

35. Curley JP, Mashoodh R, Champagne FA (2011) Epigenetics and the origins of paternal effects. Horm Behav 59: 306-314. [Crossref]

36. Bartoov B, Berkovitz A, Eltes F, Kogosowski A, Menezo Y, et al. (2002) Real-time fine morphology of motile human sperm cells is associated with IVF-ICSI outcome. $J$ Androl 23: 1-8. [Crossref]

37. Cassuto NG, Hazout A, Bouret D, Balet R, Larue L, et al. (2014) Low birth defects by deselecting abnormal spermatozoa before ICSI. Reprod Biomed Online 28: 47-53. [Crossref]

38. Teixeira DM, Barbosa MA, Ferriani RA, Navarro PA, Raine-Fenning N, et al. (2013) Regular (ICSI) versus ultra-high magnification (IMSI) sperm selection for assisted reproduction. Cochrane Database Syst Rev 7: CD010167. [Crossref]

Copyright: (C2021 Sagi-Dain L. This is an open-access article distributed under the terms of the Creative Commons Attribution License, which permits unrestricted use, distribution, and reproduction in any medium, provided the original author and source are credited. 